\title{
O JAZZ E A EDUCAÇÃO MUSICAL DO SÉCULO XX
}

\author{
Fernando Vieira da $\mathrm{Cruz}^{1}$, Joana Sanches Justo ${ }^{2}$ \\ ${ }^{1}$ Graduando do curso de Música da UNOESTE. ${ }^{2}$ Doutora em Psicologia, docente do curso de artes visuais e do curso \\ de matemática da UNOESTE. E-mail: fvccruz@hotmail.com
}

\section{RESUMO}

Este artigo apresenta uma faceta do improviso como um modo de atuar na vida e, conseguintemente, na música. Não trataremos apenas da improvisação musical, mas do improviso originado do jazz como estilo de vida e que pode ser introduzido nas aulas de música. Cabe notar que o improviso esteve presente na vida dos negros americanos e por isso viria a culminar em um estilo de música baseada no improviso musical. $O$ artigo ainda versa sobre conceitos de educação musical que surgiram no século XX acerca da criatividade musical. Por fim relaciona a aplicação das atividades de criação musical com o estilo de vida improvisado na situação do surgimento do jazz. Sendo que isso implica em tratar não apenas da improvisação musical, mas apresentar aos alunos um ambiente propício à improvisação, criando situações em sala de aula que estimulem os alunos a pensar na música de forma improvisada e espontânea.

Palavras-chave: Música. Jazz. Educação Musical. Improviso. Criatividade.

\section{INTRODUÇÃO E OBJETIVO}

O improviso sempre esteve presente em toda a história do jazz. Isso se dava em um momento específico após a exposição do tema principal da música. Após essa exposição cada instrumentista tinha um espaço de tempo, determinado por uma quantidade de compassos, para desenvolver o seu improviso, geralmente também se determinava uma sequencia para os músicos improvisarem um após o outro.

Improvisar se tornou uma tarefa natural para essas pessoas, essa naturalidade não estava restrita apenas a música, eles tinham facilidade de improvisar em tarefas comuns de seu cotidiano, porque isso lhes fora imposto ao longo de muitos anos de sua história. Isso, principalmente após o século XVII no período da escravatura. Levados para outros países e até para outros continentes, foram obrigados a viver de forma improvisada. Talvez seja esse o segredo da grande fluência em improvisação musical desse povo que deu origem à música jazz: relacionar a necessidade de improvisar com a maneira improvisada que realizavam tarefas comuns do cotidiano.

Quanto à inserção do improviso na educação infantil, consideramos que o improviso possibilita que a criança exercite a resolução de problemas e a flexibilidade diante de situações inesperadas auxiliando-a no desenvolvimento do raciocínio e da sociabilidade. 
As atividades de criação musical devem sugerir situações em que os alunos possam exercitar a resolução de questões musicais improvisando.

Essa abordagem em atividades de criação musical se apóia no pensamento sobre educação musical do século XX (FONTERRADA, 2008). Esse pensamento está baseado num tripé que diz ser necessário desenvolver três importantes aspectos dos quais depende o fazer musical: o primeiro aspecto é a execução instrumental, estando relacionado à manipulação do instrumento musical com técnica adequada. O segundo aspecto é a apreciação musical, que é uma escuta ativa, uma apreciação crítica em música. O terceiro aspecto é a criação musical, ou seja, o desenvolvimento da capacidade criativa dos alunos relacionada à música (SWANWICK, 2003).

\section{O POVO QUE DEU ORIGEM AO JAZZ}

No livro "JAZZ" de Harris (1952), que versa sobre a origem e a história do jazz, o autor traz ainda informações de mais de 500 anos da história e influências sofridas pelo povo africano que deu origem a esse novo estilo musical. A partir dessa obra pode-se observar que a música não era a única coisa que o povo da África Ocidental fazia de forma improvisada. O improviso estava presente em praticamente tudo o que eles faziam, desde os instrumentos musicais improvisados de caixas de charutos, tanques de lavar roupas, até sua comunicação durante o trabalho, work songs, que eram canções e gritos que tomavam ritmo com o bater do martelo e de outras ferramentas. Os temas dessas canções de trabalho, os "work songs", eram criados na maioria das vezes de maneira espontânea, isso, para avisar outros escravos que deviam ajudar a esconder fugitivos que passavam por aquela região.

A partir das considerações de Harris (1952) e Berendt (1975) sobre o surgimento do jazz, e os momentos que se seguiram, podemos dizer que o improviso mais do que um forma de se fazer música era uma forma de vida das pessoas que criaram esse novo estilo musical, uma vez que a música criada por esse povo nada mais era do que um reflexo da sociedade e da forma que eles viviam naquele momento.

De acordo Harris (1952), nos estados sulinos dos Estados Unidos onde o código de escravatura era muito mais rígido do que no restante do país, os escravos eram proibidos de se manifestarem culturalmente de qualquer forma que fosse a não ser pelos seus cantos de trabalho, pois seus senhores acreditavam que manuseando uma ferramenta no mesmo ritmo em que cantavam, os escravos de certa forma ignoravam o peso do trabalho e tinham maior produção.

A restrição à manifestação cultural foi apagando da memória daquele povo o conhecimento de sua própria cultura por aproximadamente 200 anos, a partir de 1865 com o fim 
da escravatura, os antigos escravos agora chamados de negros americanos formavam um povo em cuja cultura musical se formara um vácuo (HARRIS, 1952).

Em terra de estranhos, sua cultura, suas famílias e suas comunidades foram reorganizadas improvisadamente nessa nova fase de suas vidas, essa forma de vida viria a influenciar uma nova música que fora criada por esse povo, essa música tinha por base o improviso, ou seja, uma espécie de intuição musical (HARRIS, 1952).

O Dixieland, hoje, conhecido como jazz tradicional, surge em 1910 e nessa fase frisamos o surgimento de bandas de jazz compostas por americanos brancos. Porém para Berendt (1975) as características predominantes que foram se fortalecendo na consolidação da "identidade" do jazz eram de origem predominantemente dos negros descendentes dos países da África Ocidental, e essas características são oriundas da forma improvisada e autodidata de aprender música que eles desenvolveram.

\section{A EDUCAÇÃO MUSICAL NO SÉCULO XX E O MODELO DE KEITH SWANWICK}

Ao mesmo tempo em que surge o jazz como uma nova música, surge uma nova visão sobre metodologia em educação musical, e junto dessa visão surgem os "métodos ativos" em educação musical. Os métodos ativos em educação musical são propostas ou abordagens pedagógicas que surgiram no início do século XX(FONTERRADA, 2008).

Nas décadas de 1950 e 1960 surgiu a chamada segunda geração de educadores musicais dos métodos ativos na Europa e América do Norte (FONTERRADA, 2008). Entre os educadores mais importantes destacamos Keith Swanwick, autor sobre o qual falaremos adiante.

A ideia geral dos métodos ativos em educação musical está fundamentada no tripé: tocar, ouvir e criar (FONTERRADA, 2008).

O "tocar" refere-se à execução musical com técnica adequada. O que não se pode confundir dentro do novo conceito de educação musical, é que não se dá o devido valor ao desenvolvimento técnico de execução musical, porém este não é mais o único foco, o certo é que o mesmo não pode existir de forma independente ou isolada, desconsiderando a criatividade e o pensamento, ou seja, a escuta ativa como apreciação.

O "criar" monta a idéia de que o fazer musical também está relacionado á criação musical, ou seja, além de se decifrar um código musical escrito há muitos anos e interpretá-lo executando uma peça, é preciso criar improvisando, arranjando ou compondo para que o fazer musical seja completo (além de ouvir). As atividades de criação musical devem ser abordadas desde o primeiro dia de aula (SWANWICK, 2003), criando situações em que os alunos se verão não só na condição 
de explorar sua criatividade, mas na necessidade de improvisar para a resolução de tal situação. É neste momento que podemos observar uma recriação de um ambiente propício ao aprendizado da improvisação como recurso metodológico extraído da situação de onde se originou o jazz, para Swanwick (2003), as atividades de criação devem estimular a criatividade dos alunos desde a primeira aula, de acordo com o desenvolvimento da manipulação do instrumento que os alunos forem desenvolvendo.

O ouvir se refere a ouvir de maneira consciente, com escuta ativa. Para que a apreciação musical se dê de forma ativa, e não apenas passiva ou receptiva, é necessário criar um parâmetro de comparação para que os alunos ao apreciar música tenham um conhecimento prévio que sirva de motivo de raciocínio enquanto ouvem a música.

A grande diferença que há nesse novo modelo de educação musical, está relacionada a ir além da simples execução instrumental, como no século XIX onde os estudos musicais estavam voltados ao desenvolvimento técnico para execução do instrumento (FONTERRADA, 2008) e desenvolver principalmente a criatividade dos alunos.

A respeito da educação musical no século $X X$, usaremos o modelo pedagógico de Keith Swanwick intitulado de modelo CLASP: criatividade em música (C, de composition), conhecimento histórico (L, de literature studies), apreciação musical ( $A$, de audition), aquisição de técnica ( $S$, de skill aquisition) e execução instrumental ou vocal ( $P$, de performance). No Brasil, o termo foi traduzido e adaptado como modelo TECLA, ( $T$, de técnica) (E de execução) (C de composição e arranjo) (L de literatura) e (A de apreciação) (1979/2003).

Segundo o modelo de Swanwick (1979/2003) existem cinco parâmetros de experiências musicais necessárias para o fazer musical, sendo elas: técnica, execução, composição, literatura e apreciação.

Swanwick (2003) também apresenta que apenas três dos cinco parâmetros de experiências musicais são experiências musicais diretas, a saber, a composição, a execução e a apreciação, as outras duas - técnica e literatura - são atividades que servirão apenas de apoio para as três primeiras relacionadas. Aqui nós percebemos de maneira clara, que o modelo de Swanwick é baseado no tripé já apresentado, sendo que as três atividades principais de seu modelo referemse às atividades do tripé.

Dentre todos os tipos de experiências musicais apresentadas no tripé e no modelo TECLA, as que mais nos interessam são as relacionadas à criatividade. As atividades de criação passaram a ser consideradas de importância primária a partir do século $X X$, e com o surgimento do chamado tripé da educação musical no século XX. Para Swanwick (2003) as atividades de criação também 
passam a ter suma importância na formação musical dos alunos, e deve fazer parte de suas experiências musicais desde o inicio do aprendizado.

Essas atividades têm o papel inicial de estimular a criatividade dos alunos, independentemente do grau de seu conhecimento técnico em música, ou da sua capacidade mais ou menos desenvolvida em manipular ou executar um instrumento musical. Evidenciamos que o ponto mais importante não é o limite de como ser criativo em música, mas o ponto inicial de quando essa criatividade deve começar a ser estimulada.

Conforme o modelo de K. Swanwick, a execução instrumental e vocal devem ser priorizadas durante as aulas. Para Swanwick (2003) é necessário que haja fluência musical desde o inicio do processo de aprendizagem, ou seja, enfatizar as chamadas atividades musicais diretas.

Assim como as habilidades técnicas relacionadas ao manuseio do instrumento musical apoiam e complementam a execução do mesmo, o conhecimento histórico servirá de base para atividades de apreciação musical, criando um vínculo entre os alunos e a obra a ser apreciada, já os conhecimentos teóricos servirão de apoio a execução prática (SWANWICK, 2003).

\section{ESTÍMULOS À CRIATIVIDADE DOS ALUNOS}

Este trabalho trará a partir de agora uma discussão acerca de uma atividade de estímulo a criatividade dos alunos de nível iniciante, além de seus resultados e influências no comportamento do aluno dentro da sala de aula.

O que se propõe agora é que as atividades de estímulo à criatividade dos alunos sejam abordadas de maneira inesperada, ou seja, as atividades também devem ser apresentadas de forma improvisada, criando um ambiente propício aos alunos se verem obrigados a improvisar na resolução de uma situação.

A atividade que servirá de base para os resultados desse trabalho é chamada de "IMITAÇÂO e CRIAÇÂO DE FRASES", e está diretamente voltada a estimular a criatividade musical dos alunos. Essa atividade pode ser aplicada a partir da segunda ou terceira aula da turma iniciante. Ela será aplicada enquanto os alunos ainda não estão tocando com o instrumento todo montado, mas apenas utilizando de boquilhas e bocais ${ }^{1}$, os alunos já devem ser capazes de emitir sons curtos e longos, fortes e fracos com facilidade.

Usando uma boquilha ou bocal, o educador cria frases rítmicas para que os alunos o imitem em seguida respeitando uma determinada pulsação rítmica ${ }^{2}$. De início não se deve exigir a

\footnotetext{
${ }^{1}$ Pequenas peças que são encaixadas ao corpo do instrumento musical, e que são posicionadas na boca do músico.

${ }^{2}$ Ou seja, dentro de um contagem de tempos que torne possível aos alunos executarem em sincronia a atividade. 
diferenciação de sons fortes e fracos, além de que as frases devem ser simples e conter notas longas, situação em que é mais fácil controlar a embocadura. Aos poucos as frases vão ficando mais complexas e com sons mais curtos, o educador começa a exigir também as dinâmicas, diferenciando os sons fortes e fracos.

A aplicação dinâmica da atividade colocará os alunos numa situação de estímulo à espontaneidade ao tocar, como tudo é executado dentro do ritmo os alunos terão de imitar as frases tocadas pelo educador sem ter tempo para refletir sobre as mesmas, ou seja, terão de certa forma a obrigação de fazê-lo em pronta resposta. Isso exigirá uma compreensão rápida da situação apresentada, por vezes quando o aluno não puder assimilar totalmente as frases que deve imitar passará a executá-las instintivamente.

Essa atividade remonta uma situação com uma problemática que deverá ser resolvida pelos alunos. Existe o que fazer (imitar as frases apresentadas), também existe uma regra dentro da qual se deve fazer (dentro do ritmo), e em terceiro lugar a forma provável de resolver a situação não é totalmente possível uma vez que não há tempo suficiente para uma compreensão metódica da situação. Isso coloca os alunos numa situação que além de possibilitar a improvisação, exige a mesma como forma de resolução.

A partir do momento em que os alunos já estiverem respondendo as frases de forma espontânea, cada aluno passa a desempenhar o papel de criar as frases. Cada um criará uma frase, enquanto os outros alunos devem imitá-la, seguindo uma sequência pré-determinada. Deve ser exigido dos alunos que criem frases que ainda não foram usadas na atividade até então.

Essa é uma situação que se assemelha a improvisação musical no jazz, e ao tema de improviso citado anteriormente neste trabalho, é um momento em que cada aluno deverá criar, e improvisar obedecendo a uma regra pré-determinada enquanto faz música.

Após a aplicação desta atividade por algumas vezes ao longo do primeiro semestre letivo, é possível observar que os alunos passam a responder com naturalidade ás atividades propostas sendo que uma resposta espontânea a qualquer estímulo musical se torna cada vez mais natural entre os alunos.

Propor uma atividade com uma abordagem diferente das convencionais, valorizando a participação e interatividade entre os alunos não se torna mais um tabu, pois os mesmos passam a participar com naturalidade das atividades que exigem deles pró-atividade na sala de aula, mesmo que inicialmente haja um período de resistência os alunos abandonam a posição de receptores de conhecimento e passam a exercer um papel participativo na construção do saber musical e no desenvolvimento de sua espontaneidade musical. 


\section{CONCLUSÃO}

As abordagens lúdicas e dinâmicas nas atividades de estímulo a criatividade criam um ambiente descontraído e desviam gradualmente a atenção do aluno de sua timidez deixando-os cada vez mais a vontade na sala de aula de música.

A aplicação desse tipo atividade logo na primeira aula da turma iniciante tem um papel fundamental para desenvolver esse ambiente descontraído, pois é um momento em que na maioria dos casos os alunos ainda não se conhecem, e uma vez envolvidos pela "brincadeira" musical apresentam um comportamento mais espontâneo na sala de aula de música do que geralmente apresentam em outros ambientes e ou situações.

$\mathrm{Na}$ atividade apresentada, observamos um grande estimulo a criatividade musical do aluno, mesmo que amparado por conhecimentos teóricos e habilidades técnicas rasas, a atividade é eficaz no que se propõe a estimular a criatividade dos alunos iniciantes. Quanto mais profundos seus conhecimentos teóricos, e melhor desenvolvidas suas habilidades técnicas o aluno se vê em situação cada vez mais rica em possibilidades de criar, utilizando-se de mais elementos musicais disponíveis em seu conhecimento, sendo que a tarefa de criar irá se tornando cada vez mais fácil.

\section{REFERÊNCIAS}

BERENDT, J. E. O Jazz: do Rag ao Rock. tradução de Júlio Medaglia. São Paulo: Perspectiva, 1975. HARRIS, R. Jazz: as suas origens e o desenvolvimento que adquiriu, desde os ritmos primitivos africanos à evoluída música ocidental dos nossos dias. tadução de Raul Calado. Lisboa: Ulisseia, 1952.

SWANWICK, K. A basis for music education. London: Routledge, 1979.

SWANWICK, K. Ensinando música musicalmente. tradução de Alda Oliveira e Cristina Tourinho. São Paulo: Moderna, 2003.

FONTERRADA, M. T. de O. De tramas e fios: um ensaio sobre música e educação. 2.ed. - São Paulo: Editora UNESP; Rio de Janeiro: FUNARTE, 2008. 